DOI: http://dx.doi.org/10.1590/1981-7746-sol00230

\title{
DOCÊNCIA NA EDUCAÇÃO INFANTIL: NEOLIBERALISMO, DESUMANIZAÇÃO E ADOECIMENTO NA REPÚBLICA INACABADA BRASILEIRA
}

\author{
TEACHING IN PRE-SCHOOL EDUCATION: NEOLIBERALISM, DEHUMANIZATION \\ AND ILLNESS IN THE UNFINISHED BRAZILIAN REPUBLIC
}

\author{
Wagner Eduardo Estácio de Paula (D) [0000-0003-1174-9036], Rita de Cássia Gabrielli \\ Souza Lima1 iD [0000-0001-8863-542X] \\ ${ }^{1}$ Universidade do Vale do Itajaí, Programa de Mestrado Profissional em Saúde e Gestão do Trabalho, \\ Itajaí, Santa Catarina, Brasil. <rita.lima@univali.br>
}

Resumo A pesquisa que deu origem a este artigo situa-se no contexto da categoria teorética 'repúblicas inacabadas.'Teve como objetivo analisar a percepção de professores(as) de uma unidade escolar de educação infantil de um município catarinense, sobre a produção de dignidade pelo trabalho e foi realizada no segundo semestre de 2018. A coleta de dados se deu por meio de três instrumentos: entrevistas individuais, grupos focais e diários de campo. Os dados indicaram a solidão na interface entre docência na educação infantil, neoliberalismo e dignidade pelo eco das vozes dos professores que anunciam a destituição de sua produção de dignidade pelo trabalho, o que afeta direta e negativamente sua condição de saúde. Apontam-se condições para o estabelecimento dessa condição desumanizante e propõem-se o reconhecimento e o estímulo ao trabalho coletivo como ferramentas de transformação.

Palavras-chave profissão docente; educação infantil; neoliberalismo; dignidade.
Abstract The research that originated the present article is related to the context of the theoretical category of 'unfinished republics.' It had the goal of analyzing the perception of the teachers of a pre-school education unit of a municipality in the state of Santa Catarina, Brazil, regarding the production of dignity through work, and was performed in the second semester of 2018. The data was collected using three instruments: individual interviews, focus groups and field journals. The data indicate the loneliness in the interface among teaching in pre-school education, neoliberalism and dignity through the echo of the voices of the teachers who announced the dismissal of their production of dignity through work, which affects directly and negatively their health condition. We indicate the conditions for the establishment of this dehumanizing situation and propose the recognition and stimulus to collective work as tools for transformation.

Keywords teaching profession; pre-school education; neoliberalism; dignity. 


\section{Introdução}

O processo histórico da educação, em sua forma escolar, apresenta a escola como uma instituição induzida a transmitir o conhecimento para as novas gerações, com os papéis de sobrevivência da cultura - diante dos processos históricos humanos - e função diretiva do agir humano no mundo. A escola "reproduz o conhecimento para preservar a cultura" (Mori e Curvelo, 2016, p. 503).

A transmissão do conhecimento, por sua vez, em interlocução com a sua produção e preservação, tem no professor o papel central de, em qualquer instância dos níveis de educação, utilizar sua força de trabalho para produzir um bem humano: formar cidadãos. Quando se trata de formação infantil, isto é, de pequenos, condições favoráveis devem ser criadas para que o conhecimento seja absorvido e se torne "condição de cidadania" (Oliveira et al., 2013, p. 145).

Vinte e cinco séculos se passaram desde que Aristóteles concluiu seus estudos sobre a concretização da ideia de bem por cidadãos da pólis, que exigia como ponto de partida o homem bom, virtuoso. Numerosas correntes de pensamento foram geradas pelas condições de possibilidades concedidas pelos momentos históricos e respectivas formações econômico-sociais sucessivas. No entanto, dois fundamentos aristotélicos parecem preservados: o modo como se compreende uma dada realidade e o modo como se é percebido pelo coletivo que compõe a realidade, sendo que esse 'modo de', em ambos os fundamentos, afeta o humano e a própria realidade. Nesse sentido, dependendo do modo como a instituição e o(a) professor(a) compreendem o bem, isto é, a formação cidadã, eles irão percorrer, junto com os educandos, um dado caminho educacional e, nesse percurso, se transformarão. Tudo dependerá do ponto de partida, do ponto em que se quer chegar e da constelação de valores que inicia, atravessa e completa o processo.

Para que o trabalho educacional tenha como ponto de partida a consciência histórica de cidadania e como ponto de chegada a formação em cidadania, torna-se fundamental que no exercício do ofício o(a) professor(a) reconheçase e seja reconhecido em dignidade, bem como reconheça o outro de si, em ato. Essas formas de reconhecimento encontram condições de possibilidades em um Estado Democrático de Direito.

No caso do Brasil, que instaurou a República em 1889, sob uma realidade federativa sustentadora não de uma união nacional, mas de "autonomia local a potentados estaduais" (Comparato, 2007, p. 13), com ampla margem de independência a alguns poucos estados brasileiros e que, na Constituição Federal de 1988, reafirmou os entes federados como independentes em seus 
domínios próprios de ação, em que pese a heterogeneidade de pontos de partida de governos subnacionais, a democracia, como "única verdadeira salvaguarda do regime republicano" (Comparato, 2007, p 15), ainda não foi realmente consagrada. A democracia que se tem não controla o poder, mas o ornamenta, imputando a uma vasta massa nacional a desproteção de garantia a bens fundamentais.

Ainda assim, o Estado Democrático de Direito, constitucionalmente instituído em 1988, oportunizou à República Federativa do Brasil a possibilidade de concretizar um processo de reaprendizado democrático, cujo alicerce dependeria das escolhas societárias, posto que "uma Constituição é sempre uma obra em evolução e terá as dimensões que as razões contrapostas puderem suportar" (Mezzaroba e Strapazzon, 2012, p. 336). Ao se considerar que o contexto nacional era de gestação neoliberal, isto é, de gestação de "uma organização social [em defesa] do capitalismo financeiro-rentista" (Bresser-Pereira, 2018, p. 17), não fica difícil entender que escolhas democráticas hegemonizariam o alicerce de um eventual processo de reaprendizado democrático: entre 1988 e 2008, a Constituição sofreu "cinquenta e nove" remendos sem, ao menos, um único ensejo de participação popular (Comparato, 2007, p. 21).

Trinta anos se passaram e o Brasil não consagrou, na realidade, a proteção a bens fundamentais. Como uma democracia impossibilitada de amadurecer, o país pode ser compreendido como uma 'república inacabada', destituída de uma robusta tradição cultural de proteção a esses bens, tanto individuais como coletivos, em razão do vazio histórico de "compromissos éticos consensuais" para protegê-los (Mezzaroba e Strapazzon, 2012, p. 339-340).

A categoria teorética 'república inacabada' expressa necessidades e contradições de natureza política, social, econômica e cultural, que identificam historicamente o processo de formação social brasileiro. Além da ausência de uma cultura de proteção a bens fundamentais (Mezzaroba e Strapazzon, 2012), outros elementos participam da construção dessa categoria. Para citar alguns: os extensos ciclos de autoritarismo que se seguiram ao desenho institucional da República de 1889 (Faoro, 2007); um processo de evolução republicana ambíguo e contraditório, operado por uma lógica populista, oligárquica e autoritário-burocrática (Abranches, 1988); a tendência histórica por importação de ideias que, no contexto nacional, assumem a condição de "fora de lugar" (Schwarz, 2000, p. 9); e a desigualdade dos sujeitos nos limites do território nacional, o que gera uma república não efetivamente de cidadãos (Moraes, 1996). Uma república ainda imatura em seu processo de produção de bem, isto é, de formação cidadã, em sentido aristotélico.

Na perspectiva aqui defendida, a dignidade é o valor-fonte, lo scheletro da produção de bem, e se efetiva pelo trabalho, ou seja, na "atividade teóricoprática do que fornece o ponto de partida para o posterior desenvolvimento de uma concepção histórica, dialética, do mundo" (Gramsci, 2007, p. 1.541). 
A pesquisa apresentada neste artigo situa-se no contexto da categoria teorética 'repúblicas inacabadas'. Teve por objetivo analisar a percepção de professores(as) de uma unidade escolar de educação infantil, de um município catarinense, sobre a produção de dignidade pelo trabalho. Assume-se dignidade como um produto humano imaterial, com potência intersubjetiva, fundamental para a condição humana e produzido na dinâmica das relações. Um produto construído, percebido e reconhecido por sujeitos concretos porque históricos e afetados pela respectiva formação social do momento histórico.

\section{Em pauta, a dignidade da pessoa humana}

Não se pretende retomar aqui a história da ideia de dignidade da pessoa humana no pensamento filosófico ocidental, até porque seria impossível para os estreitos limites deste texto, mas apresentaralgumaslinhas teóricas sobre o tema.

Foi com Immanuel Kant que se completou a secularização da dignidade da pessoa humana (Sarlet, 2007). Para a teoria moral kantiana, discorrida na Fundamentação da Metafísica dos Costumes, ${ }^{1}$ a dignidade é um valor absoluto da pessoa que tem por fundamento a autonomia da vontade do ser racional (Granato, 2014). Nessa obra, Kant sustenta que o ser racional se chama pessoa, pois "existe como um fim em si mesmo, não simplesmente como meio para o uso arbitrário desta ou daquela vontade" (Kant, 2007, p. 68).

Ao fazer uso de vários exemplos, ele argumenta que quando se imprime uma vontade boa (vontade em si) às ações, uma vontade autônoma, importando-se não com o resultado, mas com a atitude, tem-se a possibilidade de se distanciar de interesses egoístas (Kant, 2009), nos quais a vontade é boa meramente para outra coisa, como um meio, e tratar a humanidade "sempre e ao mesmo tempo como fim" (Kant, 2009, p. 14). Essa condição de possibilidade não serve somente a "moralistas militantes", como se apenas estes sejam "fins em si/tenham dignidade", posto que a própria ação moral não pode ser certificada (Granato, 2014, p. 636). Na Fundamentação, Kant (2009, p. 9) diz que "a moralidade, e a humanidade enquanto capaz de moralidade, é a única coisa que tem dignidade". Nesse sentido, de cunho moral, o valor das ações que uma pessoa dirige a outras pessoas e também a si mesma não é condicional, mas supremo. "No reino dos fins tudo tem ou um preço ou uma dignidade [...] quando uma coisa está acima de todo o preço, e, portanto, não permite equivalente, então tem ela dignidade" (Kant, 2009, p. 68-69).

Em contraposição, o pensamento gramsciano vê a teoria moral kantiana como "uma falsa universalização", uma universalização "estática", constituindo-se "em uma tipologia de comportamento ligada e circunscrita a uma determinada cultura [...] a grupos particulares", isto é, uma universalização que não "valoriza o gênero humano inteiro", ao fazer passar por moral "so- 
mente aquilo que, de modo conformista, cada um julga que possam e devam fazer não propriamente todos os seres humanos, mas somente a maioria dos que pertencem à sua cultura" (Finelli, 2017, p. 453-454). No Caderno 11, 58, 1484, Gramsci diz que a máxima kantiana "pressupõe um conformismo mundial [...] É possível dizer que a [sua] máxima está ligada a seu tempo, ao Iluminismo cosmopolita e à concepção crítica do autor" (Gramsci, 2007, p. 1.484). No entanto, Gramsci atribui uma importância enorme à filosofia de Kant, como filosofia de "síntese a priori", isto é, "da capacidade do ser humano ser princípio de síntese e de produção de sentido no mundo", isto é, da capacidade de "tornar o próprio conhecer uma função do agir e do sintetizar" (Gramsci, 2007, p. 1.067).

Estudos analíticos realizados no século XX sobre a dignidade da pessoa humana, em âmbito jurídico-institucional, sinalizaram que, embora a sua estética seja incontestável, a expressão dignidade da pessoa humana tem marcas de "ambiguidade e porosidade" (Rocha, 1999, p. 24), além de carregar um conteúdo controverso, de difícil definição e compreensão: não é um conceito passível de ser positivado pelo direito, mas pode por este ser reconhecido e protegido (Borella, 1999).

No âmbito da doutrina alemã, Günter Dürig (1956) qualificou a dignidade da pessoa humana como elemento intrínseco desta, "irrenunciável e inalienável [...], de tal sorte que não se pode cogitar a possibilidade de determinada pessoa ser titular de uma pretensão a que lhe seja concedida a dignidade", embora esta possa ser violada. No entanto, o reconhecimento da dignidade como "valor próprio de cada pessoa não resulta, pelo menos não necessariamente (ou mesmo exclusivamente), em uma biologização da dignidade" (Sarlet, 2007, p. 366).

A condição de inerente a todo e qualquer ser humano fez com que a dignidade passasse a ser usualmente definida como "constituindo o valor próprio que identifica o ser humano como tal" (Sarlet, 2007, p. 364). Mesmo assim, Tischner (1987) adverte, em sua linha compreensiva, que "não restam dúvidas de que a dignidade é algo real, algo vivenciado concretamente por cada ser humano, já que não se verifica maior dificuldade em identificar claramente muitas das situações em que é espezinhada e agredida" (Sarlet, 2007, p. 364).

Ainda na perspectiva da ordem jurídico-constitucional, o fato de a dignidade ser intrinsecamente integrada como parte da pessoa humana, posto que, "em princípio, todos [...] são iguais em dignidade, no sentido de serem reconhecidos como pessoas" [...], é preciso reconhecer que nem sempre as pessoas se comportam "de forma igualmente digna nas suas relações com seus semelhantes, inclusive consigo mesmo", podendo as pessoas serem sujeitos de "atos dignos e indignos". Mesmo assim, "a dignidade de todas as pessoas, mesmo daquelas que cometem as ações mais indignas e infames, não poderá ser objeto de desconsideração" por parte do direito (Sarlet, 2001, p. 44). 
De fato, o artigo $1^{\circ}$ da Declaração Universal dos Direitos Humanos, da Organização das Nações Unidas, dispôs que "todos os seres humanos nascem livres e iguais em dignidade e direitos", universalizando neste preceito os pressupostos de base da doutrina kantiana, exposta na Fundamentação (ONU, 1948).

Na linha compreensiva de Pérez Luño, citado por Sarlet (2007, p. 370), a dignidade do ser humano tem "uma dimensão intersubjetiva", por meio da qual pode ser possível desenvolver comunitariamente mecanismos de impulsão à produção comunitária de dignidade, em cujo processo cada pessoa poderá se reconhecer e ser reconhecida em dignidade, em relação com os demais que se encontram na mesma circunstância. Essa compreensão tem como ponto de partida o reconhecimento não do ser individual, mas da condição básica do ser - a vida em relação com os outros -, o que não significa advogar, com essa linha, a funcionalização da dignidade, ou seja, a defesa "de sacrifícios da dignidade pessoal em prol da comunidade" (Sarlet, 2007, p. 370).

Em La dignidad de la persona como fundamento del ordenamiento constitucional español, Martínez (1996, p. 81) defende a ideia de que a dignidade não atua apenas como um direito individual declarado por um princípio constitucional, mas também como um "direito objetivo" que baliza os direitos fundamentais; "que se traduz no dever geral de respeitar os direitos dos outros e os seus próprios".

Em uma linha similar, Landa (2002, p. 112) sinaliza que a dignidade não é somente "um valor e princípio constitucional, mas também um dínamo dos direitos fundamentais; por isto, serve de parâmetro fundamental [para a] atividade do Estado e sociedade".

Visitando as cinco constituições promulgadas no Brasil republicano, observa-se que o termo dignidade não está presente nas de 1891, 1934 e 1937, aparecendo pela primeira vez no texto da Constituição de 1967, em seu artigo 157: "a ordem econômica tem por fim realizar a justiça social, com base nos seguintes princípios [...] II - valorização do trabalho como condição da dignidade humana" (Brasil, 1967). Já a Constituição de 1988 declarou enfaticamente em seu artigo $1^{\circ}$ a dignidade humana como fundamento do Estado Democrático de Direito (Brasil, 1988).

A partir de então, a dignidade da pessoa humana transformou-se em um fundamento para toda a nação, gerando a necessidade de o ordenamento jurídico ser repensado e reelaborado, para que à pessoa humana fossem asseguradas "condições políticas, sociais e econômicas que permitam que ele atinja os seus fins" (Rocha, 1999, p. 27), sendo o fim o próprio homem. Essa lógica passa por todas as nuances da vida do homem, inclusive a do trabalho e suas particularidades dentro do sistema de produção desigual capitalista. 


\section{Percurso para uma análise sobre produção de dignidade pelo trabalho}

De natureza qualitativa, caráter descritivo-interpretativo e análise ético-política, o processo de investigaçãoaconteceu com quinze professores(as) deum núcleo de educação infantil que integra, juntamente com outros dois núcleos, uma unidade escolar localizada em um bairro de vulnerabilidade social de um município catarinense. No censo realizado pelo Instituto Brasileiro de Geografia e Estatística (IBGE) em 2010, a população total desse bairro era de 10.570 habitantes (IBGE, 2010), nos últimos anos, sua população aumentou expressivamente em virtude do crescimento econômico da cidadee da vinda de imigrantes, predominantemente haitianos.

Utilizou-se de amostra intencional para a seleção dos participantes por meio de convites. Os critérios de inclusão previamente definidos para a seleção de professores(as) foram: ser professor ativo no núcleo de educação infantil, selecionado pela conveniência; e ter experiência docente de, pelo menos, dois anos com o público infantil. Todos os convidados aceitaram participar da pesquisa.

Três instrumentos foram utilizados: diário de campo, entrevista semiestruturada e grupo focal. Com o diário de campo obtiveram-se importantes informações como: rotina e horários dos professores, tempo de atuação, modo de organização do núcleo de educação infantil e perfil dos alunos. A entrevista semiestruturada se deu por meio de um roteiro temático, orientado por oito questões norteadoras criadas pelos pesquisadores. Já o grupo focal contou com nove questões e foi realizado em dois turnos: professores do período matutino (oito) e vespertino (sete). Após a análise de três entrevistas-piloto, realizaram-se pequenos ajustes no instrumento.

A coleta aconteceu no período de novembro a dezembro de 2018, no local escolhido pelos participantes: dependências do núcleo de educação infantil, lócus do trabalho cotidiano. $O$ instrumento da entrevista semiestruturada teve como diretriz o ato de pensar a dignidade e a produção de dignidade pelo trabalho por meio de temas mais conhecidos objetivamente pelos participantes: relação saúde-doença-trabalho, doenças do trabalho, medicalização de padrões sociais e relações interpessoais do processo familiar e trabalho. Já o instrumento coletivo assumiu um caráter filosófico ao elencar temas relacionais: relação trabalhador-instituição, relação saúde-trabalho, relações interpessoais do processo de trabalho, relação do professor com condições de trabalho, relação entre trabalho e valorização profissional, produto gerado pelo trabalho, estigmas sociais, o sentido de dignidade, o lugar ocupado pela dignidade no trabalho e se dentro da prática há algum modo por meio do qual se possa perceber a produção de dignidade.

O material foi registrado por meio de uso de gravador e posteriormente transcrito. No total, foram nove horas e 24 minutos de gravações. 
O anonimato das participantes da entrevista individual foi garantido por meio do uso da abreviatura $\mathrm{P}$, seguida por numeral arábico, e das participantes do grupo focal com a abreviatura FP, seguida também por numeral arábico. O documento final das transcrições foi organizado e codificado por meio da análise temática de conteúdo ajustada. $\mathrm{O}$ ajustamento da técnica foi necessário em razão de o estudo não ter previsto a investigação da frequência das mensagens expressas em palavras, expressões ou frases, mas a significância de argumentos e ideias apreendidos, independentemente do número de vezes em que se fizeram manifestar (Minayo, 2014).Os dados foram classificados por meio das etapas previstas pela análise temática. Após a codificação, os códigos atribuídos às unidades de registro, com base em critério semântico, foram agrupados por analogia. Em seguida, explorou-se transversalmente o material e, por fim, fez-se a convergência dos dados, visando à etapa de categorização, em um esforço de síntese (Minayo, 2014). Emergiram duas categorias: 'De à espera de ao mover-se para' e 'Solidão, na interface entre docência na educação infantil, neoliberalismo e dignidade'. Neste artigo, é discutida a segunda categoria.

O estudo foi apreciado e aprovado pelo Comitê de Ética em Pesquisa com Seres Humanos da Universidade do Vale do Itajaí, Santa Catarina, Brasil, sob o parecer de número 2.777.683, de 19 de julho de 2018, e Certificado de Apresentação para Apreciação Ética (CAAE) n. 92431218.7.0000.0120.

\section{Análise do eco de vozes da 'ferramenta' professor; em xeque, a produção de dignidade em seu trabalho}

Aapresentaçãodosresultadoseadiscussãosedarãoemumformatoensaístico, pois assume-se que são as falas dos autores, nas quais estão incorporadas as dos participantes, que conduzirão o processo de interpretação e análise - "uma fala polifônica", portanto (Duarte, 2004, p. 218). Algumas unidades deregistroserão expostaseminterlocução comomarcoteórico-conceituale perspectivas dos autores.

A solidão, manifesta na pesquisa aqui apresentada, não corresponde à ausência de pessoas ou companhia. A categoria foi gerada na interface entre a docência, o neoliberalismo e a dignidade da pessoa professor, elevando-se para além da constatação simplista de uma pessoa que está isolada, que passa muito tempo sem a companhia de seus pares. Solidão aqui não remete somente a pessoas, visto que, mesmo só, uma pessoa pode não se sentir em nenhum momento solitária. É pensando o inverso: pessoas que estão sempre rodeadas de outras, com seu lar e seu trabalho cheios de vozes múltiplas, mas, em seu interior, estão completamente solitárias. 
A solidão tratada aqui está ligada diretamente ao termo individualismo, exaustivamente debatido no contemporâneo e enaltecido pela lógica neoliberal vigente.

Dentro dos muros escolares, muitas são as vozes que falam; no entanto, essas vozes somente ecoam, poucas são ouvidas realmente pelas instituições envolvidas, cabendo citar: unidade-gestão escolar, família, poder público muncipal, colegas, secretarias e governo. É esse eco que ousamos chamar de solidão.

A solidão docente aparece quando, no cotidiano do trabalho, o ser professor sente-se invisível. Quando todas as razões de educar desaparecem. As relações de acompanhamento e ampliação da educação pela família desaparecem. Perante os problemas específicos do ofício de professor, os órgãos públicos responsáveis desaparecem. Resta apenas o professor, sua sala de aula e o aluno.

Aluno. Este tem lugar especial na vida do professor: "Acho que é esse o nosso papel: acreditar no ser humano e fazer com que ele próprio acredite nele" (FP4). Na educação pública infantil, o professor toma para si, somente para si, todas as suas dores e flagelos gerados por negligências, pois as demais instituições desaparecem. No momento em que os toma para si, o professor não é mais o responsável para contribuir com a educação deste ser; ele passa a ser o único responsável pela criança, em todos os seus aspectos, apreendendo seus problemas existentes e também os que surgirão no futuro, em forma de dever.

Nessa conjuntura neoliberal, em que bem-estar social e direitos trabalhistas são assaltados (Brasil, 2016, 2017), o professor é obrigado a transpassar o limite de sua humanidade. Ele não consegue - nem é visto como quem consegue -, efetivamente, educar: "A questão de infraestrutura a gente sabe que é péssima, a autonomia não existe, nada disso que tem no papel a gente tem aqui, não depende da gente!" (FP9). Ao transpassar esse limite de humanidade, o professor transfere-se, conscientemente - por circunstâncias das condições de trabalho - de humano para máquina. Ele deixa de exercer seu papel de professor e exerce, por hora, papel de pai, mãe, gestor escolar, secretário de educação, psicólogo familiar, assistente social e toda função que sente necessária, naquele distinto momento de seu trabalho. Entra em ação o professor mecânico, o ser máquina, aquele que tem de fazer, pois todas as tarefas estão concentradas nele. E como máquina, é substituível quando quebra, tem baixo valor mercadológico, não tem reconhecido seu verdadeiro papel, seu prestígio social se perde ano após ano e, finalmente, sua dignidade é destituída.

Máquina não tem dignidade, tem preço, diz $\operatorname{Kant}(2007,2009)$ em Fundamentação. O professor-máquina percebe-se um custo nas planilhas dos contadores. Aos poucos, o ser professor-máquina sente de maneira mais forte e clara o desgaste, e seu papel de educar, dia a dia, é apagado pelas muitas obrigações imputadas. Quando o ser professor-máquina se dá conta, aparecem no corpo os efeitos, em forma de sinais, das relações sociais de produção: séries de lesões osteomusculares e uma diversificada gama de distúrbios psicológi- 
cos: "Estou esgotada, as energias estão todas sugadas, muito estressante. Pra dormir é só abaixo de Rivotril, tenebroso" (FP11). E ele, mais uma vez, está só. Como ele, muitos vivenciam a mesma solidão, não raramente, no mesmo ambiente, na mesma escola. A lógica neoliberal vigente, financeiro-rentista, não dá trégua. Sedenta por "rendimentos do capital (juros, dividendos e rendas imobiliárias elevadas)", atua em busca de novas formas de lucro para as instituições financeiras e agrava profundamente as desigualdades sociais (Bresser-Pereira, 2018, p. 24). Essa lógica silencia a república por fazer, leva ao individualismo doentio, não adoecendo o'ser per se', mas o ser em seu cotidiano. Transforma pessoas em máquinas. Destitui-Ihes a dignidade, apequenando seu estar no mundo.

Para entender todo esse movimento que afeta diretamente $o$ atual docente da educação infantil, é importante buscar laços históricos que sustentem essa conjuntura. A educação infantil, para Didonet (2001), tem origem no trinômio mulher-trabalho-criança. Tal etapa da educação, portanto, não tinha caráter pedagógico, mas puramente assistencialista. É importante ressaltar que essa assistência à infância é um marco histórico de suma importância, pois foi a partir dela que crianças inglesas com menos de nove anos de idade passaram a ser reconhecidas como crianças, no contexto de expansão da Revolução Industrial na Inglaterra. Conforme relata Engels (1975, p. 220), a legislação laboral inglesa de 1833 "proibiu o trabalho das crianças menores de 9 anos nas fábricas da Inglaterra". No entanto, outras faixas etárias deveriam cumprir longas jornadas de trabalho, a exemplo de crianças entre 9 e 13 anos, que trabalhavam 48 horas semanais.

No contexto brasileiro, não foi diferente. A educação infantil, reconhecida antigamente por 'creche', sempre foi ligada à assistência (principalmente) da mãe trabalhadora. Somente com a Carta Magna de 1988 o direito à educação para a criança foi garantido como direito social fundamental. Em seu artigo 208, a Constituição dispôs o dever do Estado de prestar educação escolar pública, conferindo à efetividade desse direito "a consistência de suas ações" (Machado, 2018, p. 1.078).

Atualmente, muitos são os olhares, pensamentos, intenções, vontades e documentos institucionais que buscam garantir uma educação infantil de qualidade para a criança, em relação dialética com a realidade social em que se encontram os muitos núcleos de educação infantil espalhados pelo Brasil. Neste breve contexto histórico, um pensamento emerge: como é caracterizada a ação docente nessa etapa da educação?

Num passado recente, o profissional envolvido com essa atividade tinha a função apenas de cuidar, prestar assistência. Hoje, com uma forte vertente pedagógica pautada nas principais teorias pedagógicas, a exemplo das teorias críticas como a histórico-cultural, que considera o aluno como ser histórico, crítico e central no processo educativo, esse profissional concebe-se docente. 
Docente-cuidador. Docente-professor. Unidos por uma linha tênue, compulsivamente tensionada pelas armadilhas do homem-máquina.

Quando indagada sobre a relação entre saúde e trabalho, P15 desabafou: "Porque como tu não vai ter a saúde afetada com trinta crianças que precisam de você integralmente! Se você está doente ou se você não está... se está disposta ou se não está, eles precisam de você o tempo todo!"

A resposta da profissional sinaliza preocupação com a integridade dos seus alunos, mas chama para si toda a responsabilidade, inclusive se acometida for por alguma doença. Por não haver outros professores para substituí-la, ela sente-se na obrigação de deixar uma possível patologia ou agravo não interferir no seu papel docente, aceitando, com conformismo, que uma eventual doença sua não pode comprometer a produção. Máquina não pode quebrar.

Outro problema que torna a solidão uma companhia cativa na vida do professor é o quantitativo de alunos em sala: "Eles colocam uma sala com uma quantidade de criança e a gente tem que dar conta. Tem que dar conta porque esse é o nosso trabalho, e se a gente não der conta é um mau profissional" (P15).

O fragmento "uma quantidade de criança e a gente tem que dar conta", muito recorrente nas entrevistas, expressa um dos modos de conceber o próprio trabalho em sociedades capitalistas dependentes: não como "a própria realização e produção da sua vida" (Marx, 1844, apud Abbagnano, 2007, p. 1.149), mas como subsunção institucional. O docente-máquina, ao contrário do docente-cuidador-professor, parece não encontrar condições de possibilidades para assumir e exigir, diante de si e das instituições envolvidas, que para exercer um bom trabalho o docente precisa de condições (dignas) favoráveis - por exemplo, um quantitativo razoável de crianças. Um número excessivo faz com que o conhecimento, muitas vezes conquistado arduamente nos anos de universidade, torne-se inviável de ser aplicado na prática. Esse real é motivo de grande frustração para o profissional, que não vê resultado significativo em seu trabalho, o que se reflete na produção de sua dignidade.

A crítica quanto ao excessivo número de alunos em sala reflete a solidão de outro lado dessa esfera social: a família - a economia doméstica. Cada vez mais os pais, mães, avós e responsáveis pela criança têm que trabalhar para conseguir condições mínimas de vida. Muito longe de países que conquistaram o Welfare State, longas são as jornadas para a conquista de moradia, alimentação e acesso a serviços. Logo, as vagas em núcleos de educação infantil tornam-se covardemente moedas de troca de votos utilizadas todos os anos por candidatos. Vale notar a curiosidade: muito frequentemente, as conversas não se voltam para a busca de estratégias de qualificação da educação, mas para a quantidade de matrículas: 
[...] isso é um carro político. Então você tem que estar toda vida cuidando pra pai não ir pra rádio, pra pai não falar mal, porque é pra passar a impressão que a Prefeitura está fazendo o papel dela com escola, comida, com material... nem que seja o mesmo material o ano inteiro, o mesmo material, só fita dupla face e folha de sulfite, porque outros materiais que a gente precisa não tem (FP12).

Na ponta dessa situação está o professor que se sente só, carregando sobre os ombros a culpa de não conseguir lecionar da forma como sonha e acredita.

Esse problema, entretanto, não afeta somente as condições de trabalho do professor pela superlotação das salas de aula. Ao avaliar mais profundamente a situação, percebe-se que o professor assume outros e diversos papéis no cotidiano do trabalho:

Falta de um amparo, por conta que a educação infantil faz com que tu tenha que dar um suporte tanto para a família quanto para a criança hoje em dia. Então a genterecebefamílias muito desestruturadase a genteacaba tendo quefazeropapel de família e professora (P4).

Quando a entrevistada diz que não há amparo, evidencia a forma individual com que o professor é obrigado a assumir problemas que não são de caráter pedagógico. As famílias do(a) aluno(a), cada vez mais assumindo distintas configurações, muitas delas formadas precocemente, muitas vezes não têm acesso a serviços públicos que auxiliem na instrução e apoio na criação de um infante. P4 expressou:

[...] hoje em dia é muito terceirizado. É muito fácil, hoje em dia, ter um filho. Você tem um filho, mas então você transfere a responsabilidade, e a responsabilidade passa a ser do professor ou da instituição que está responsável pela criança. E muitas vezes a instituição não tem o suporte pra te dar, então acaba pesando somente para o professor.

Nesta fala-denúncia de papéis, a participante compartilha que o(a) professor(a) muitas vezes é obrigado(a) a assumir integralmente a criança, no tempo em que ele(a) está com ela, no papel de mãe/pai. Somando-se a ausência de condições estruturais e materiais, e mesmo de apoio institucional, o professor se depara, em um grupo de aproximadamente vinte crianças, com uma ou várias que necessitam de maior atenção e cuidado. Essa(s) criança(s) pode(m) ficar até 12 horas sob sua responsabilidade, sendo que o turno total de trabalho, 12 horas, é dividido em duas equipes de docentes, seis horas cada. Ao assumir esse papel, mesmo se de forma involuntária, o(a) professor(a) também estará só novamente. A fala da professora P16 é um retrato do sentimento que esse profissional carrega em si: "Então eu passo a deixar de ser um ser humano pra 
ser um instrumento da sociedade" - uma ferramenta social, portanto. Essa compreensão ganhou força ao reverberar nos dois debates coletivos produzidos pela aplicação dos grupos focais. Aqui abre-se um parêntese para dialogar com uma perspectiva sobre as determinações explicativas do neoliberalismo que alteraram substancialmente as estruturas econômicas domésticas brasileiras.

Em busca do modo como são constituídas as determinações explicativas sobre as reformas que delimitaram o neoliberalismo no Brasil, Massimo (2013) analisou criticamente a produção bibliográfica publicada no periódico Dados durante os anos 1990, década em que foram desenhados os arranjos institucionais que conformam a atual estrutura de competição política, dos desenvolvimentos econômico e social brasileiros. Ao isolar a estrutura lógica de 38 artigos por meio de três ferramentas - o problema, o objeto (o que o problema explica) e a tese - e relacionar essas estruturas com seus óculos interpretativos e analíticos, o autor identificou três linhas de argumentação: argumentos sociológicos, aqueles que buscam as determinações das reformas neoliberais na sociedade; argumentos pragmáticos, cujas explicações estão atreladas à inexorabilidade das reformas; e argumentos institucionalistas, que buscam as explicações nas instituições políticas nacionais. Inspirando-se em Sebastião Velasco, o autor apresenta cinco conjuntos de reformas que protagonizaram o neoliberalismo: abertura comercial; liberalização financeira; liberalização do regime de investimentos estrangeiros; privatização de serviços públicos e empresas estatais; e desregulamentação do mercado de trabalho.

Expõe a relação com os dados que a gestão de um núcleo de educação infantil, até o presente momento, funciona da seguinte maneira: existe uma equipe formada por um administrador escolar, um supervisor e um coordenador. O coordenador não é eleito por um colegiado gestor ou aprovado em um processo seletivo; diferentemente dos dois outros cargos, ele é indicado. Essa indicação se dá por intermédio da orientação de vereadores eleitos da base aliada do governo em exercício, constituindo, portanto, o chamado cargo comissionado. Não cabe aqui fazer juízo de valor da situação, mas esse registro é importante, porque quem está exercendo a função nem sempre está apto, com competências e habilidades, para o exercício. Tal fato, favorecido pela desregulamentação do mercado de trabalho, se reflete no sentimento de solidão por parte do corpo docente. Ao ser questionada por possíveis estigmas sociais atribuídos ao professor, P08 disse: "Quando a gente pede um apoio, uma ajuda, que precisa de alguma coisa, às vezes não é bem vista. [...] Já está reclamando, já está pedindo." Esse 'pedir apoio' está direcionado ao cargo de gestão, e por desconhecimento esse gestor nega auxílio por julgar irrelevante o pedido do professor. 
Quando apresentada a uma situação hipotética, em que a professora entrevistada poderia fazer um pedido a alguém de um alto cargo do governo, para mudar algo que está afetando a produção e o seu reconhecimento em dignidade, a fala de $\mathrm{P} 11$ reforçou um sentimento de indignação com relação à escolha do gestor da unidade escolar:

Olha... a gente fica até meio assim de falar, né... mas acho que tirar esses cargos comissionados que tem aí, políticos, e colocar pessoas que já estão aptas ao trabalho, que já vivenciaram, já estiveram em sala de aula.

Também assim foi a fala, indignada, da professora P09: "A única coisa que eu iria pedir é: esquece a política aqui dentro! [...] Eu acho que aqui não poderia ter ninguém indicado, ele tinha que ser preparado pra isso."

Um gestor é a voz e principalmente o ouvido de todo um grupo de professores. Esses profissionais precisam de voz e vez - nos debates e decisões sobre os rumos da própria unidade escolar e também da educação como plano municipal. O eco não ouvido de suas vozes apaga o sentimento de pertencimento, de protagonismo em uma unidade comprometida com uma educação de qualidade, conforme se espera. Esse apagar do sentir-se pertencendo se reflete na desvalorização do sonho, criatividade e anseios do professor, que, na condição de só, tenta, sem muito sucesso, implementar em sua prática isolada o que poderia ganhar maior alcance se devido e, coletivamente, respaldado pela equipe gestora.

O individualismo traduzido no sentimento de solidão também acompanha o professor na relação com a saúde. Qualquer atividade laboral não é isenta de riscos, mas o questionamento é: qual o limiar ético do risco do trabalhador em paralelo com os benefícios coletivos/sociais do fruto do seu trabalho? Essa questão remete a um importante pensador sardo, da ética e bioética cotidiana: Giovanni Berlinguer. Em Bioética cotidiana, Berlinguer (2015, p. 152) assinala que "as dificuldades podem tornar-se dramáticas para os trabalhadores quando o seu poder é escasso, quando o Estado é inerte, quando as empresas baseiam a sua atividade numa ausência de regras e de respeito à vida humana".

Nessa linha compreensiva, inúmeros são os exemplos de professores que possuem um ou mais agravantes patológicos que interferem negativamente em seu estado de saúde. Por um bem maior - a educação das crianças -, o professor, com as dadas condições, adoece. Esse pensamento é traduzido pela fala da professora P16, que, ao ser questionada sobre seu atual estado de saúde relacionado com seu trabalho, disse: "A gente sobrevive, né? Tem que vir trabalhar - se está com dor ou está sem dor. As crianças não merecem, e é isso que a gente tem, tem que oferecer o melhor da gente." Os casos são realmente muitos e até mesmo dispensam uma coleta formal de dados em que se exponha a doença relacionada ao professor. Desde sintomas típicos de lesão 
por esforço repetitivo e distúrbio osteomuscular relacionado ao trabalho até a síndrome de burnout e problemas psicológicos, o professor coleciona cada vez mais males.

No momento do acometimento de males ligados à sua saúde, o professor também experimenta a sensação de solidão, uma vez que não reconhece, na maioria das vezes, o Sistema Único de Saúde (SUS) como um patrimônio seu, nosso, de todos os brasileiros. Provocada para compartilhar se acredita no SUS, P2 revelou: "Não. Não por causa da espera. Como a gente tem plano de saúde, a gente acaba nem contando mais com o SUS." Na mesma lógica, P11 relatou: "Meu pai também tinha (SUS) [...] ele já tinha falecido quando saiu um exame que ele tinha pra fazer. Olha o tempo que já tinha demorado! [...] Eu acho muito precário nosso sistema de saúde. É terrível."

Os problemas com a saúde pública no Brasil estão longe de se resolverem, visto que o descaso com patrimônios de proteção social, imputado pelo neoliberalismo e pelas medidas de austeridade tomadas e previstas, cada vez mais solidifica o desmonte do SUS, e afoga a possibilidade de qualificação das redes de atenção à saúde por meio da coordenação de um sistema regulador responsivo. As pessoas morrem antes de seus exames serem garantidos.

Barros e Amaral (2017) identificaram os desafios da regulação em saúde no âmbito tanto do SUS como do sistema de saúde suplementar. No âmbito do SUS, destacaram-se: o baixo investimento público em saúde e a concorrência do setor privado, na representação de planos e seguros de saúde, com o setor público. Não bastassem os expressivos benefícios de renúncia fiscal, o setor privado, incorporado ao SUS pela Constituição de 1988 como um subsistema complementar, é hoje, escancaradamente, concorrente do SUS.

Tanto nas entrevistas individuais como no grupo focal, professores deram uma entonação singular ao expor a palavra reconhecimento, conotando um valor negativo para o que sentem com relação ao termo. Na unidade escolar em que a pesquisa foi desenvolvida, equipe gestora, família, secretaria de educação e as mais variadas esferas do governo não inspiram o reconhecimento do trabalho do professor. P08 comentou:

Aí eu penso: meu Deus, a gente está fazendo de tudo, muito mais que em casa, e às vezes a gente se quebra sozinha em sala de aula, que falta gente, às vezes uma pessoa fica sozinha em sala de aula, tenta fazer tudo sem pedir nada pra secretaria, aqui pra direção - pra gente não incomodar, e no final ainda a gente sente que não está sendo valorizado nessa parte.

Esse fato não é específico do grupo social analisado na pesquisa aqui apresentada; está no dia a dia, em que a competição excessiva e o espírito competitivo empreendedor, tão difundidos e endeusados pelas premissas neoliberais, não permitem que se reconheça em dignidade o outro de si. 
$\mathrm{Na}$ atual conjuntura sociopolítica, o reconhecimento não é valorizado, pois, em sua individualidade, o professor sempre pensa que está fazendo menos, que não deve ousar a incomodar, como disse P08.

A exemplo de P09, a percepção é mais dolorida ainda: "A gente, infelizmente, é frágil, e a gente precisa de reconhecimento." A frase é autoexplicativa. Para o mundo neoliberal, fragilidade é ter seu trabalho reconhecido por outras pessoas. A contradição aqui merece, definitivamente, reconhecimento. No contexto da categoria teorética 'república inacabada', é possível inferir que a fome manifestada por esse reconhecimento não é uma realidade específica da força de trabalho aqui analisada, mas a expressão de um recorte de uma sociedade que ainda não alcançou efetivamente a condição cidadã; de uma sociedade marcada por grandes descontinuidades e desigualdades em sua estrutura social. Um caminho fértil para a produção desse reconhecimento pode ser forjado, citando Pérez Luño (1995), pela criação de um movimento comunitário pelo coletivo de professores capaz de impulsionar, por meio da intersubjetividade, a produção comunitária de dignidade entre iguais que estão na mesma condição.

Com a supremacia da ideologia neoliberal, para a qual os mercados moderadamente competitivos, que compõem o capitalismo do tempo presente, podem garantir "crescimento, estabilidade financeira e justiça econômica" (Bresser-Pereira, 2018, p. 22), o produto não poderia ser outro: "perderam espaço as questões políticas e jurídicas da dignidade humana, visto que os poderes estatais têm sua autonomia reduzida" (Oliveira, 2008, p. 97).

Com um Estado absolutamente apequenado e uma lógica financeiro-rentista acima dos bens comuns, mínima também é a preocupação com ambientes educacionais, uma vez que seu caráter é tido como não lucrativo, custoso, fonte de prejuízo, sob o olhar neoliberal em que tudo se reduz a números. 0 local onde foi realizado o estudo é gerido pelo poder municipal, assim como todas as unidades escolares de educação infantil públicas do país; logo, com um Estado diminuto, pouco se valoriza, tanto em questões de investimento como em questões de dignidade, o trabalho do professor.

O professor, figura importante no processo educacional, sofre com um jogo de forças não visíveis e muitas vezes não perceptíveis por ele próprio, sendo que o modelo neoliberal estimula uma forma de pensamento em que não há outra forma de se ver o mundo. Com isso, docentes-cuidadores-professores ficam à deriva. Ações ordenadas entre grupo de professores, pais e comunidade escolar podem servir de impulso para mudanças positivas com relação à produção de dignidade pelo professor de educação infantil, a exemplo de um modo de fortalecimento da democracia, com relação à escolha de gestores e novas políticas públicas, que valorizem e reconheçam o ser professor como humano e não como ferramenta social. 
Profissão docente. Na área da educação infantil. Tantas contradições, sentimentos, males, lágrimas e sorrisos. Muitos são os desafios a serem transpassados, mas o impulso inicial deve vir de dentro do perímetro escolar. Individualmente, nada será alcançado em questão de avanço nessa complexa temática, mas por meio da organização coletiva será possível transformar ecos em vozes ativas, vozes essas que clamam por dias melhores num Brasil altamente desigual. Vozes que, dia a dia, mesmo com as condições adversas, buscam, pela educação, um meio de superação social.

São tantas as contradições que é difícil socializá-las nos limites deste texto. A solidão sentida no eco das vozes não pode ser sufocada pela onda individualizante do neoliberalismo. Conforme destacou, de maneira bela e melancólica a professora P16, no contexto de um trabalho em excesso, fins de semana de planejamentos e conclusões de atividades e uma rotina acalorada: "É um misto de prazer e culpa".

\section{Considerações finais}

Neste artigo, analisou-se a percepção de professores(as) de um núcleo de educação infantil sobre a produção de dignidade pelo trabalho, no contexto da categoria teorética 'repúblicas inacabadas'.

Na relação com os dados, constatou-se que essa produção é atravessada pela solidão. Por uma forma de solidão que aparece quando, no cotidiano do trabalho, o ser professor de pequenos sente-se invisível, pouco ouvido pelas instituições envolvidas com seu trabalho, cabendo citar: unidade-gestão escolar, família, poder público municipal, colegas, secretarias e governo. Nessa solidão, manifestada pelo eco das próprias vozes, os professores anunciam a destituição de sua produção de dignidade pelo trabalho, o que afeta direta e negativamente sua condição de saúde.

O estudo destacou a necessidade de ampliação do debate acerca do tema por meio de ações motivadoras dentro dos núcleos educacionais, a fim de impulsionar, concordando com Pérez Luño (1995), o fortalecimento da dimensão intersubjetiva entre os docentes que se encontram em condições similares, com vistas à produção comunitária de dignidade, o que acaba desaguando na produção de sentido no mundo. Em um mundo de ideologia neoliberal, que insiste no agravamento das desigualdades sociais e no comando dos direitos pelo mercado.

Enquanto não houver amadurecimento republicano em direção a uma sociedade efetivamente cidadã, que faça valer, de fato, a legitimidade da soberania popular e o Estado Democrático à maneira brasileira, a força de trabalho educacional - leia-se o(a) professor(a) de educação infantil - não estará coletivamente municiada de referências morais robustas para reivindicar a produção perene de dignidade no trabalho. 
DOCENCIA EN LA EDUCACIÓN INFANTIL: NEOLIBERALISMO, DESHUMANIZACIÓN Y ENFERMEDAD EN LA REPÚBLICA INACABADA BRASILEÑA

Resumen La pesquisa que dio origen a este artículo se relaciona al contexto de la categoría teórica“repúblicas inacabadas".Tuvo como objetivo analizar la percepción de profesores(as) de una unidad escolar de educación infantil de un municipio del estado de Santa Catarina, Brasil, sobre la producción de dignidad por el trabajo, y fue realizada en el segundo semestre de 2018. La recolección de datos se dio por medio de tres instrumentos: entrevistas individuales, grupos focales y diarios de campo. Los datos indicaron la soledad en la interconexión de docencia en la educación infantil, neoliberalismo y dignidad por el eco de las voces los profesores que anuncian la destitución de su producción de dignidad por el trabajo, lo que afecta directa y negativamente su condición de salud. Se indican condiciones para el establecimiento de esa situación deshumanizante y se proponen el reconocimiento y el estímulo al trabajo colectivo como herramientas de transformación.

Palabras clave profesión docente; educación infantil; neoliberalismo; dignidad.

\section{Colaboradores}

WagnerEduardo Estácio de Paula contribuiu para a concepção, planejamento, análise e interpretação, e participou da aprovação da versão final do manuscrito. Rita de Cássia Gabrielli Souza Lima contribuiu para a concepção, planejamento, análise, revisão e participou da aprovação da versão final do manuscrito.

\section{Nota}

' Original: Fundamentação da metafísica dos costumes - Grundlegung zur Metaphysik der Sitten (GMS). Riga: Akademie Ausgabe, 1785. 


\section{Referências}

ABBAGNANO, Nicola. Dicionário de filosofia. São Paulo: Martins Fontes, 2007.

ABRANCHES, Sérgio. Presidencialismo de coalizão: o dilema institucional brasileiro. Dados, Rio de Janeiro, v. 31, n. 1, p. 5-34, 1988.

BARROS, Fernando P. C.; AMARAL, Tereza C. L. Os desafios da regulação em saúde no Brasil. Anais do Instituto de Higiene e Medicina Tropical, Lisboa, v. 16, supl. 3, p. S39-S45, 2017.

BERLINGUER, Giovanni. Bioética cotidiana. Brasília: Universidade de Brasília, 2015.

BORELLA, François. Le concept de dignité de la personne humaine. In: PEDROT, Philippe (dir). Ethique, droit et dignité de la personne. Paris: Economica, 1999. p. 37.

BRASIL. Constituição da República Federativa do Brasil de 1967. Disponível em: <http:// www.planalto.gov.br/ccivil_03/Constituicao/ Constituicao67.htm>. Acesso em: 4 mar. 2019.

BRASIL. Constituição da República Federativa do Brasil de 1988. Brasília: Senado Federal, 1988. Disponível em: <http://www.planalto. gov.br/ccivil_03/constituicao/constituicao. htm>. Acesso em: 31 jul. 2019.

BRASIL. Presidência da República. Casa Civil. Subchefia para Assuntos Jurídicos. Emenda constitucional n. 95, de 15 de dezembro de 2016. Altera o Ato das Disposições Constitucionais Transitórias, para instituir o Novo Regime Fiscal, e dá outras providências. Disponível em: <http://www.planalto.gov.br/ccivil_03/ constituicao/emendas/emc/emc95.htm>. Acesso em: 19 maio 2019.

BRASIL. Senado Federal. Projeto de lei da Câmara n. 38, de 2017 - Reforma Trabalhista. Altera a Consolidação das Leis do Trabalho (CLT), aprovada pelo decreto-lei n. 5.452, de $1^{\circ}$ de maio de 1943 , e as leis n. 6.019 , de 3 de janeiro de 1974, 8.036, de 11 de maio de 1990, e 8.212, de 24 de julho de 1991, a fim de adequar a legislação às novas relações de trabalho. Disponível em: <https://www25. senado.leg.br/web/atividade/materias/-/ materia/129049>. Acesso em: 19 maio 2019.

BRESSER-PEREIRA, Luiz C. Capitalismo financeiro-rentista. Estudos Avançados, São Paulo, v. 32, n. 92, p. 17-29, 2018.

COMPARATO, Fábio K. Prefácio. In: FAORO, Raymundo. A República inacabada. São Paulo: Globo, 2007. p. 13, 15.

DIDONET, Vital. Creche: a que veio, para onde vai. In: BANDIOLI, Anna; MANTOVANI, Susanna. Educação infantil: a creche, um bom começo - manual de educação infantil de 0 a 3 anos: uma abordagem reflexiva. Tradução Rosana Severino di Leone e Alba Olmi. 9. ed. Porto Alegre: Artmed, 2001. p. 151-155.

DUARTE, Rosália. Entrevistas em pesquisas qualitativas. Educar, Curitiba, n. 24, p. $213-$ 225, 2004.

ENGELS, Friedrich. A situação da classe trabalhadora na Inglaterra. Porto: Afrontamento, 1975.

FAORO, Raymundo. A República inacabada. São Paulo: Globo, 2007.

FINELLI, Roberto. Kant, Immanuel. In: LIGUORI, Guido; VOZA, Pasquale (orgs.). Dicionário gramsciano. São Paulo: Boitempo, 2017. p. 453-454

GRAMSCl, Antonio. Quaderni del carcere. 3. ed. v. 2: A cura di Valentino Gerratana. Torino: Einaudi, 2007.

GRANATO, Marcelo A. Quem habita a dignidade da pessoa humana? A fundamentação kantiana. Revista da Faculdade de Direito, Universidade de São Paulo, São Paulo, v. 109, p. 623-639, 2014.

INSTITUTO BRASILEIRO DE GEOGRAFIA E ESTATÍ́sTICA (IBGE). Censo demográfico 
2010. Disponível em: <https://sidra.ibge. gov.br/Tabela/608\#resultado>. Acesso em: 4 mar. 2019.

KANT, Immanuel. Fundamentação da metafísica dos costumes. Tradução Paulo Quintela. Lisboa: Edições 70, 2007.

KANT, Immanuel. Fundamentação da metafísica dos costumes. Tradução Guido Antônio de Almeida. São Paulo: Discurso Editorial, Barcarolla, 2009.

LANDA, César. Dignidad de la persona humana. Questiones Constitucionales, Cidade do México, n. 7, p. 109-138, 2002. Disponível em: <http:// www.redalyc.org/pdf/885/88500704.pdf>. Acesso em: 6 maio 2018.

LUÑO, Antonio E. P. Derechos humanos, estado de derecho y constitución. 5. ed. Madri:Tecnos, 1995.

MACHADO, Costa (org.). Constituição Federal interpretada. 9. ed. São Paulo: Manole, 2018.

MARTíNEZ, Miguel A. A. La dignidad de la persona como fundamento del ordenamiento constitucional español. León: Secretariado de Publicaciones de la Universidad de León, 1996.

MASSIMO, Lucas. Como se explica o neoliberalismo no Brasil? Uma análise crítica dos artigos publicados na revista Dados. Revista de Sociologia e Política, Curitiba, v. 21, n. 47, p. 133-153, 2013.

MEZZAROBA, Orides; STRAPAZZON, Carlos L. Direitos fundamentais e a dogmática do bem comum constitucional. Sequência, Florianópolis, n. 64, p. 335-372, jul. 2012.

MINAYO, Maria C. S. O desafio do conhecimento: pesquisa qualitativa em saúde. 14. ed. São Paulo: Hucitec, 2014.
MORAES, Filomeno. Direitos e garantias fundamentais e a realidade brasileira. In: TRINDADE, Antonio A. C. A incorporação de normas internacionais de proteção dos direitos humanos no direito brasileiro. San José, Costa Rica: IIDH, ACNUR, CIVC, CUE, 1996. p. 471-484.

MORI, Rafael C.; CURVELO, Antonio A. S. O pensamento de Dermeval Saviani e a educação em museus de ciências. Educação e Pesquisa, São Paulo, v. 42, n. 2, p. 491-506, 2016.

OLIVEIRA, Danilo. O neoliberalismo como contraestímulo à realização da dignidade humana. Argumenta Journal Law, Jacarezinho, v. 8, n. 8, p. 91-102, 2008.

OLIVEIRA, Terezinha et al. Escola, conhecimento e formação de pessoas: considerações históricas. Políticas Educativas, Porto Alegre, v. 6, n. 2, p. 145-160, 2013.

ORGANIZAÇÃO DAS NAÇÕES UNIDAS (ONU). Declaração Universal dos Direitos Humanos. 1948. Disponível em: <https://www.ohchr.org/ EN/UDHR/Documents/UDHR_Translations/ por.pdf>. Acesso em: 4 mar. 2019.

SARLET, Ingo W. Dignidade (da pessoa) humana e direitos fundamentais na Constituição Federal de 1988. Porto Alegre: Livraria do Advogado Editora, 2001.

SARLET, Ingo W. As dimensões da dignidade da pessoa humana: construindo uma compreensão jurídico-constitucional necessária e possivel. Revista Brasileira de Direito Constitucional - RBDC, São Paulo, n. 9, p. 360-388, 2007.

SCHWARZ, Roberto. Ao vencedor as batatas. São Paulo: Duas Cidades, 2000. 